\title{
Evaluation of Trichoderma spp for the Biocontrol of Moniliophthora perniciosa Subgroup 1441
}

\author{
Maria Lucia Garcia Simões (corresponding author) \\ Dept. de Ciências Naturais, Universidade Estadual do Sudoeste da Bahia \\ Estrada do Bem Querer Km 4, Vitória da Conquista, Bahia, Brazil \\ Tel: 55-77-3424-8655 E-mail: marialuciags@ig.com.br
}

\author{
Sâmia Maria Tauk-Tornisielo \\ Centro de Estudos Ambientais, Universidade Estadual Júlio de Mesquita Filho \\ Avenida 24, n. 1515, Rio Claro, São Paulo \\ Tel: 55-19-3534-0122Ｅ-mail: seb@rc.unesp.br
}

Givaldo Rocha Niella

CEPLAC (Comissão Executiva do Plano da Cultura Cacaueira)

Km 22, Rod. Ilhéus/Itabuna, Ilhéus, Bahia

Tel: 55-73- 3214-3000Ｅ-mail: gniella@ cepec.gov.br

Daniel Mario Tapia Tapia

Núcleo Complexo Produtivo em Saúde, Universidade Federal da Bahia, C. Anísio Teixeira

R. Rio de Contas, n. 58, Vitória da Conquista, Bahia

Tel: 55-77-3429-2709_E-mail:dmttapia@yahoo.com

Received: November 20, 2011 Accepted: December 5, 2011

doi:10.5296/jbls.v3i1.1097ＵRL: http://dx.doi.org/10.5296/jbls.v3i1.1097 


\section{Abstract}

Trichoderma species, isolated from different producer regions of cocoa (Bahia, Brazil), were evaluated as for their capacity of usage in the biocontrol of the basidiomycete Moniliophthora perniciosa subgroup 1441, which causes the witches' broom in cocoa. The isolates of Trichoderma were evaluated through individual indices so called \%AP (Antagonistic Potential to Moniliophthora perniciosa subgroup 1441), \%PG (Potential Growth in vitro) and \%PSPr (Potential of Spore Production on rice) These indices were evaluated together, also they were used for the determination of Biological Control Potential (\%BCP) of each antagonistic specie to the evaluated pathogen. Afterwards, the ability of the antagonistic to colonize and to produce spores on sterilized dry brooms was also evaluated. Some of the isolates Trichoderma spp showed a high \%AP to the pathogen and high \%PG, but did not present a significant \%PSPr, turning impossible the spore production for biocontrol at commercial level. Significant differences were found within the individual indices among the species and isolates of the same species of Trichoderma spp, pointing out a great genetic variability among them. Trichoderma harzianum 911 showed to have the best biocontrol potential to the pathogen when compared to the other isolates, presenting a \% BCP of $91.86 \%$ (mainly by the high \%AP of $97,76 \%$ ) a \%PSPr of $99.53 \%$, also producing $22.67 \mathrm{x}$ $10^{9}$ spores. $\mathrm{mL}^{-1}$ by dry broom segment. Trichoderma harzianum 911 showed to be as promising isolate for future researches on biocontrol of cocoa witches' broom.

Keywords: Trichoderma spp, Moniliophthora perniciosa, Witches' broom, Biological control

\section{Introduction}

In Brazil and other Latin American countries witches' broom caused by Moniliophthora perniciosa (Stahel) Singer (class Basidiomycota, ord. Agaricales, fam. Tricholomataceae) is the most devastating disease of cocoa (Aime and Phillips 2005). The control of the disease cannot be completely achieved by a single method. The most commonly used control strategies include phytosanitization, application of fungicide and genetic resistance are still the main tools for controlling this disease (Bastos 1996b), nevertheless; fungicides have many undesirable attributes. Novel biocontrol agents have therefore been researched and Trichoderma (class Ascomycota, ord. Hypocreales, fam. Hypocreaceae) isolates have been the best choice (Holmes et al. 2004). Its action on the pathogen is a result of various mechanisms acting synergistically, such as competition for nutrients and space, mycoparasitism through the production of a hydrolytic enzymes and antibiosis via antibiotic metabolites (Di Verena 2006). The initial stage for the development of a biofungicide agent starts with a search for an isolate in a collection that show antagonistic capability to a plant pathogen and the success of all in the subsequent stages depends on the ability of the procedure to search and identify an appropriate candidate (Gardener and Fravel 2002). One of the main issues found is based on the fact that the results obtained may select isolates that present a good capacity of mycoparasitism, but antibiosis (and vice-versa) or even isolates with both antagonism capacities but do not offer ideal characteristics for production in commercial scale, such as, production of spores, rate of germination and velocity of 
mycelium growth, besides high productivity on the selected substrate for mass production. The integrated management of witches' broom disease involves phytosanitary pruning, which consists on the removal of the infected brooms. However, in particularly appropriate conditions, the pathogen in the brooms changes to its sexual cycle producing basidiocarps, releasing their spores consequently disseminating the disease. Thus, dry witches' broom is the target of spores pulverization, aiming their fast decomposition and the pathogen elimination. This way, an isolate that presents in vitro good qualities, cannot present a good growth on the infected brooms. Therefore, the objective of this study was to propose a more accurate in vitro method for the selection of antagonistic isolated of Trichoderma spp to $M$. perniciosa subgroup 1441, by determination of Antagonism Potential (\%AP), Potential Growth (\%PG) and Potential of Spores Production in rice (\%PSPr) indices, when evaluated together they determined the Potential for Biological Control (\%BCP), which are also representatives in the selection of an isolate, also considering its ability of colonization and sporulation on witches' broom.

\section{Materials and methods}

\subsection{Microorganisms}

An isolate of Moniliophthora perniciosa subgroup 1441, herein designated Mp1441 and ten species of Trichoderma: T. virens (Tvi2007), T. viride (Tvr905), T. atroviride (Tat2076), T. harzianum (Th1070), T. harzianum (Th911), T. pseudokoningii (Tps1052), T. pilulliferum (Tp1925), T. stromaticum (Ts3454), T. longibrachiatum (Tlg3188) and T. reesei $(\mathrm{Tr} 1612)$ isolated from different producer regions of cocoa (Bahia, Brazil), were used in the experiments. The isolates were obtained from the culture collections of the Centro de Pesquisas do Cacau - CEPEC, CEPLAC, Ilhéus, Bahia, Brazil. All the isolates were cultivated in Potato Dextrose Agar (PDA) at $24 \pm 2^{\circ} \mathrm{C}$, in which for Trichoderma spp (Tspp) 8 days in 12 hours photoperiod and Mp1441 25 days in a dark room, with the aim to obtain young colonies for studies on antagonism, sporulation, germination and rate of mycelium growth.

\subsection{Paired culture test of Tspp and Mp1441}

A $0.5 \mathrm{~cm}$ diameter disc of a 25-day old PDA containing mycelium of Mp1441 was removed and transferred to plate $(9 \mathrm{~cm})$ containing PDA and placed $1.0 \mathrm{~cm}$ from the margin. Eight days later, a $0.5 \mathrm{~cm}$ PDA disc containing mycelium and spores of Trichoderma spp, was removed from the margin of the 8-day-old culture plate and placed at $1 \mathrm{~cm}$ on the opposite margin of the plate, where the Mp1441 colony was previously inoculated, afterwards the plate was incubated at $24 \pm 2{ }^{\circ} \mathrm{C}$, over a 12-hour- photoperiod for 25 days. One plate containing only Mp1441, under the same conditions, constituted the control. Three plates were used for each treatment.

2.3 Method of observation and measurement of Tspp and Mp1441 radial growth in dual culture

The plates with the dual culture of Tspp and Mp1441 were photographed using a digital camera Kodak Easy Share every 5 days for 25 days and the images edited using Photoshop 
CS2 software version 9.0, using the appropriate tools for editing a record of the pathogen's colony growth and antagonism. The radii of Tspp and Mp1441 colonies were undertaken using a virtual ruler - Desktop Ruler version 3.0, in which the measurements could vary from 0 to $7.5 \mathrm{~cm}$, once the inocula block had $0.5 \mathrm{~cm}$ diameter and they were located on the opposite side of the plate $(9.0 \mathrm{~cm})$ and at $1.0 \mathrm{~cm}$ from the margin.

\subsection{Antagonistic potential (\%AP) of Tspp on Mp1441 in vitro}

The antagonistic potential (\%AP) of Tspp on Mp1441 was obtained by applying the formula: $\% \mathrm{AP}=(\mathrm{MP}+\% \mathrm{ATP}) / 2 \quad(\% \mathrm{MP}:$ mycoparasitism potential of Tspp on Mp1441, \%ATP: antibiosis potential of Tspp on Mp1441). The mycoparasitism potential (\%MP) of Tspp was determinate by its growth capacity on the pathogen colony on paired culture, that is, when presented a radial growth (RAC) of $7.5 \mathrm{~cm}$. The percentages that represent this capacity can only be $100 \%(\mathrm{RAC}=7.5 \mathrm{~cm})$ or $0 \%(\mathrm{RAC}<7.5 \mathrm{~cm})$. The antibiosis potential of Tspp (\%ATP) on Mp1441 on paired culture test was calculated by the percentage reduction of Mp1441 colony diameter when compared to controls (Lilly and Barnett 1951). The results were expressed in mean percentage of inhibition on the pathogen (\%ATP), obtained by applying the modified formula of Edington et al. (1971): \%ATP= $100 \mathrm{x}$ [RPC-(RFP-RIP)/RCP, where: RPC: radius of the pathogen colony control- $25^{\text {th }}$ day culture, RFP: radius of final pathogen colony- $25^{\text {th }}$ day culture on dual culture with Tspp, RIP: radius of initial pathogen colony still without the antagonist- 8th day culture.

\subsection{Potential growth (\%PG) of Tspp in vitro}

The potential growth (\%PG) of Tspp in vitro was obtained by applying the formula: $\% \mathrm{PG}=$ (\%MGP+\%SPp+\%SGP)/3, where: \%MGP: Mycelial Growth Potential, \%SPp: Sporulation Potential in plate and \% SGP: Spores Germination Potential). To determine the \%MGP of Tspp one $0.5 \mathrm{~cm}$ diameter disk of PDA containing mycelium and spores of each species of Trichoderma evaluated were transferred individually (triplicate) to the center of a Petri dish containing PDA and incubated at $24 \pm 2{ }^{\circ} \mathrm{C}$, after that a 24 and 48 - hour- measurement of the colony were undertaken. The mycelial growth velocity (MGV) of Tspp was registered applying the formula of Lilly and Barnett (1951) cited by Jackisch-Matsuura and Menezes (1999): MGV= (G2-G1/ (T2-T1), where: MGV: mycelial growth velocity; G2: growth (cm) after $48 \mathrm{~h}$ of incubation; G1: growth $(\mathrm{cm})$ after $24 \mathrm{~h}$ of incubation; T2: $48 \mathrm{~h}$; T1: $24 \mathrm{~h}$ ). The determination of the mycelial growth potential (\%MGP) was based on the isolate that presented $100 \%$, which correspond to the highest rate of growth, and applied to calculate the percentages of the other isolates. To establish the \%SPp of Tspp, the spore production in plates (SPp) was evaluated by collecting a $0.5 \mathrm{~cm}$ block in diameter from the center, in the intermediate region and periphery of culture plates of 8 days containing mycelium and spores of Tspp. For each treatment, samples from 3 plates were collected. These samples were transferred individually to test tubes containing $10 \mathrm{ml}$ of a sterilized mixture 1:1 solution $\mathrm{NaCl}(0.89 \%, \mathrm{p} / \mathrm{v})$ and Tween $80 @(0.1 \%, \mathrm{v} / \mathrm{v})$. The tubes were shaken in an electric shaker and the resultant suspension passed through 4 layers of sterile gauze to separate the mycelia fragments from the spores. Counting of the conidia was done in a Neubauer chamber with an optical microscope at 400 magnification, using dilutions of the suspension as needed. The 
calculations of SPp were undertaken applying the formula of Spier (2005). The calculation of $\% \mathrm{SPp}$ was based on the isolate that presented the highest rate of sporulation (SPp), being considered as showing $100 \%$ of SPp, using this parameter the percentages of sporulation of the other isolates were calculated. In order to determine the \%SGP, the conidial viability of the Tspp was quantified using a micro-culture and examined directly on the slide. Three circles were made on the inferior side of the slide, and on the inverse side, each circle was covered with a fine layer of a $2 \%$ water Agar. The culture medium of each circle, received individually a $0.25 \mu \mathrm{l}$ of suspension of conidia of Tspp $\left(1 \times 10^{7}\right.$ spores. $\left.\mathrm{ml}^{-1}\right)$ and the slides transferred to a humid chamber, within a Petri dish $(10 \mathrm{~cm})$ containing a moistened filter paper with $15 \mathrm{ml}$ of water. The percentage germination was evaluated after 15-hour incubation at $24 \pm 2^{\circ} \mathrm{C}$, and germination was interrupted by the addition of $1 \mathrm{ml}$ solution of blue Amann (lacto phenol/cotton blue). Spores Germination (SG) of was determined when the germ tube was equal or greater than its least diameter (Cheah and Horlock 2007). Each treatment had three replicates, ensuring a total 300 spores sampled. The calculation of germination potential (\%SGP) was based on the isolate that presented the highest rate of germination, which was considered as $100 \%$, this determination was used to calculate the percentages of the other isolates.

\subsection{Potential of Spores Production (\%PSPr) of Tspp in rice as substrate}

Polypropylene bags $20 \times 30 \mathrm{~cm}$ received $100 \mathrm{~g}$ of white rice and $60 \mathrm{ml}$ of distilled water. The unused border of the bags were folded twice and sealed with 3 staples, and then the bags were autoclaved for $30 \mathrm{~min}$. and cooled for $24 \mathrm{~h}$. After cooling, the rice in the bags that resulted in clumping were manually separated and homogenized and $6 \mathrm{ml}$ solution of spores at a concentration of $1 \times 10^{7}$ spores $\mathrm{ml}^{-1}$ of species of Trichoderma evaluated, repeated in triplicate. The bags were incubated at $24 \pm 2{ }^{\circ} \mathrm{C}$, at a photoperiod regime of $12 \mathrm{~h}$ up to rice was colonized, after that the staples on the bags were removed, opened and the substrate again homogenized, left opened. The bags were incubated under the same conditions mentioned above for 3 days, after that, $5 \mathrm{~g}$ of the rice of each bag were transferred aseptically to a sterile $250 \mathrm{ml}$ Erlenmeyer, added with $100 \mathrm{ml}$ of solution of T80® (0.1\%) and shacked for $3 \mathrm{~h}$, subsequently the spores were recovered by filtering the suspension through a gauze folded 4 times. The conidia were counted in a Neubauer chamber with optical microscope at 400 magnification, using dilutions of the suspension as needed and the determination of spore production (SPr) per gram of dry substrate (spores $\mathrm{gds}^{-1}$ ) was calculated. The spores production potential in rice (\% PSPr) as substrate was calculated considering the isolate that showed highest SPr by gram of dry substrate, so the percentages of the other isolates was determined using the parameter mentioned before. The determination of spore productivity per day was calculated taking under consideration the values of the productivities obtained and the time (days) in which the each isolated took to colonize the substrate.

\subsection{Tspp Potential for biological control of Mp1441 (\%BCP) on Mp1441}

The determination of the Tspp potential for using in biological control was obtained by the formula: $\% \mathrm{BCP}=(\% \mathrm{AP}+\% \mathrm{PG}+\% \% \mathrm{PSPr}) / 3$, where: $\% \mathrm{AP}$ : antagonistic potential, $\% \mathrm{PG}$ : potential growth and \%PSPr: potential of spores production in rice. 


\subsection{Infection of sterilized witches' broom segments by Mp1441}

The sterilization was performed using dry witches' broom segments of about 0.7 to $1 \mathrm{~cm}$ diameter and $\pm 5 \mathrm{~cm}$ length infected with $M$. perniciosa were soaked in tap water for $1 \mathrm{~h}$ to increase the moisture percentage and then disinfected by using a solution of sodium hypochlorite $1 \%(\mathrm{v} / \mathrm{v})$. Afterwards they were submerged $1 \mathrm{~h}$ in sterilized distilled water, conditioned in polypropylene bags and autoclaved at $121^{\circ} \mathrm{C}$ for 30 minutes twice at $24 \mathrm{~h}$ intervals. To test whether the segments of a determined group of witch's broom did not present contamination by $M$. perniciosa, 5 segments were saturated for 5 minutes using sterilized distilled water and incubated in Petri dishes covered with two layers of filter paper and $5 \mathrm{ml}$ of sterilized distilled water. The Petri dishes were sealed with parafilm and incubated at $24 \pm 2^{\circ} \mathrm{C}$ for 10 days. The absence of white mycelium emerging from the distal ends of the segments indicated absence of infection. The sterilized dry brooms segments were soaked into sterile distilled water in beakers during 20 to 30 minutes in order to increase the moisture content up to $40 \%$ approximately. A homogeneous mixture constituted by vermiculite $(40 \mathrm{~g})$, wheat bran $(50 \mathrm{~g}), \mathrm{CaSO}_{4} \cdot 2 \mathrm{H}_{2} \mathrm{O}(12 \mathrm{~g}), \mathrm{CaCO}_{3}(1.5 \mathrm{~g})$ and $120 \mathrm{ml}$ of water were added to the jars, then sealed and autoclaved at $121^{\circ} \mathrm{C}$ for 30 minutes. The medium was cooled and aseptically homogenized after that the jars were individually inoculated with a 6-block-PDA with $0.5 \mathrm{~cm}$ diameter containing a 20-day- colony of Mp1441, which was previously incubated at $24^{\circ} \mathrm{C} \pm 2{ }^{\circ} \mathrm{C}$ for 15 days at a 12-hour-photoperiod. After the colonization, the surface was inoculated with 5 segments of moistened sterile brooms, so that, one of its distal ends were in touch with the colonized substrate. The jars were then incubated at $24 \pm 2{ }^{\circ} \mathrm{C}$ at a 12-hour-photoperiod up to the colonization of the brooms. White mycelium emerging from the cut ends indicated infection.

\subsection{Sporulation of Tspp on sterilized brooms infected by Mp1441}

To test the ability of Tspp to germinate and sporulate on dry brooms of cocoa stem segments infected by Mp1441 were individually sprayed with a suspension of conidia of Tspp $\left(1 \times 10^{7}\right.$ conidia. $\mathrm{ml}^{-1}$ ) at the rate of $1 \mathrm{ml}$ of suspension per centimeter of broom tissue. The stem segments were then placed in deep Petri plates $(100 \mathrm{~mm}$ in diameter and $80 \mathrm{~mm}$ in depth) containing two layers of sterile filter paper and moistened with $10 \mathrm{ml}$ of sterile distilled water. There were three segments per plate. The plates were sealed with parafilm and kept at $24 \pm$ $2{ }^{\circ} \mathrm{C}$ at a 12-hour-photoperiod for 14 days up to the segment colonization. The experiment, consisting of three treatment combinations (treated with Tspp and untreated). To test the sporulation, all broom stem segments were removed and placed in flasks in which distilled water was added at the rate of $10 \mathrm{ml}$ per broom segment. The flasks were agitated for 10 minutes and the spores were counted in a Neubauer chamber and the number of spore per $\mathrm{ml}$ was calculated.

\subsection{Statistical analysis}

All obtained data for antagonistic tests, mycelial growth, and sporulation and witches' broom colonization were subjected to normality test and ANOVA. Comparison of the means was done by Tukey's range test. All statistical analysis was performed with SPSS ver.17 statistical software (SPSS, Chicago, IL). All experiments were analyzed separately. 


\section{Results}

\subsection{Potential growth (\%PG) of Tspp in vitro}

The results of mycelial growth velocity (MGV), spores germination (SG) and spores production in plate (SPp) of Thrichoderma spp in vitro are presented in Table1.

Table 1. Mycelial growth velocity (MGV), Spores germination (SG) and Spores production in plate (SPp) of Tspp in vitro

\begin{tabular}{|c|c|c|c|}
\hline Trichoderma spp & $\begin{array}{c}\text { MGV } \\
\left(\mathrm{cm} .24 \mathrm{~h}^{-1}\right)\end{array}$ & $\begin{array}{c}\text { SG } \\
\text { (at each } 100 \\
\text { counted spores) }\end{array}$ & $\begin{array}{c}\mathrm{SPp} \\
\left(\mathrm{x} 10^{8} \text { spores. } \mathrm{mL}^{-1} \text {.) }\right.\end{array}$ \\
\hline Tpl925 & $4.32( \pm 0.01)^{\mathrm{A}}$ & $100( \pm 0.00)^{\mathrm{A}}$ & $2.68( \pm 0.06)^{\mathrm{G}}$ \\
\hline Tvr2007 & $3.79( \pm 0.005)^{C}$ & $99( \pm 1.00)^{\mathrm{B}}$ & $8.38( \pm 0.04)^{\mathrm{B}}$ \\
\hline Tvi905 & $2.86( \pm 0.05)^{\mathrm{G}}$ & $94( \pm 1.00)^{C}$ & $9.39( \pm 0.07)^{\mathrm{A}}$ \\
\hline Tat2076 & $3.64( \pm 0.03)^{\mathrm{D}}$ & $74( \pm 3.60)^{\mathrm{G}}$ & $4.43( \pm 0.06)^{\mathrm{E}}$ \\
\hline Th911 & $3.61( \pm 0.05)^{\mathrm{E}}$ & $90( \pm 1.00)^{\mathrm{E}}$ & $5.80( \pm 0.07)^{\mathrm{D}}$ \\
\hline Th1070 & $2.24( \pm 0.03)^{\mathrm{I}}$ & $93( \pm 1.00)^{\mathrm{D}}$ & $6.23( \pm 0.07)^{\mathrm{C}}$ \\
\hline Tpl3188 & $3.42( \pm 0.00)^{\mathrm{F}}$ & $84( \pm 1.15)^{\mathrm{F}}$ & $3.78( \pm 0.04)^{\mathrm{F}}$ \\
\hline Ts3454 & $2.30( \pm 0.00)^{\mathrm{H}}$ & $65( \pm 3.60)^{\mathrm{H}}$ & $1.98( \pm 0.05)^{\mathrm{I}}$ \\
\hline Tps 1052 & $3.84( \pm 0.00)^{\mathrm{B}}$ & $62( \pm 2.00)^{\mathrm{I}}$ & $2.31( \pm 0.06)^{\mathrm{H}}$ \\
\hline $\operatorname{Tr} 1612$ & $1.44( \pm 0.06)^{\mathrm{J}}$ & $27( \pm 2.60)^{\mathrm{J}}$ & $0.64( \pm 0.02)^{\mathrm{J}}$ \\
\hline
\end{tabular}

Tp1925 presented the highest MGV $\left(4.32 \mathrm{~cm} .24 \mathrm{~h}^{-1}\right)(\mathrm{p}<0.05)$, showing a SG of a 100 germinated spores in 15 hours of incubation, however, presented a low SPp $\left(2.68 \times 10^{8}\right.$ spores. $\left.\mathrm{mL}^{-1}\right)$. The opposite happened with Tvi905, which presented a SPp of $9.39 \times 10^{8}$ spores. $\mathrm{mL}^{-1}$ $(\mathrm{p}<0.05)$, but showed a low MGV $\left(2.86 \mathrm{~cm} .24 \mathrm{~h}^{-1}\right)(\mathrm{p}<0.05)$. The worst results were shown by $\operatorname{Tr} 1612$ for all the evaluated parameters. Th911 e Th1070, although being isolates from the same specie showed significantly different results in all the evaluated parameters $(p<0.05)$.

The results of \%MGP (Mycelial Growth Potential), \%SGP (Spores Germination Potential), \%SPp (Sporulation Potential in plate) and \%PG (Potential Growth) of Tspp are depicted in Figure 1.

It is observed that Tvi2007 did not show the best \%MGP and \%SPp, but presented the best \%PG (91.74\%), followed by Tvr905 (86.41\%), in which there was a significant difference between them $(\mathrm{p}<0.05)$.

Hence, these isolates presented in their conjunct a good mean of the individual capacities of growth, sporulation and germination. Although, Tp1925 presented \%MGP and \%SGP of $100 \%$ did not show a good \%SPp obtaining a low \%PG, while isolates Ts3454 e Tr1612 in general, did not present good characteristics (Table 1), obtaining the lowest values of \%PG (Figure 1). 


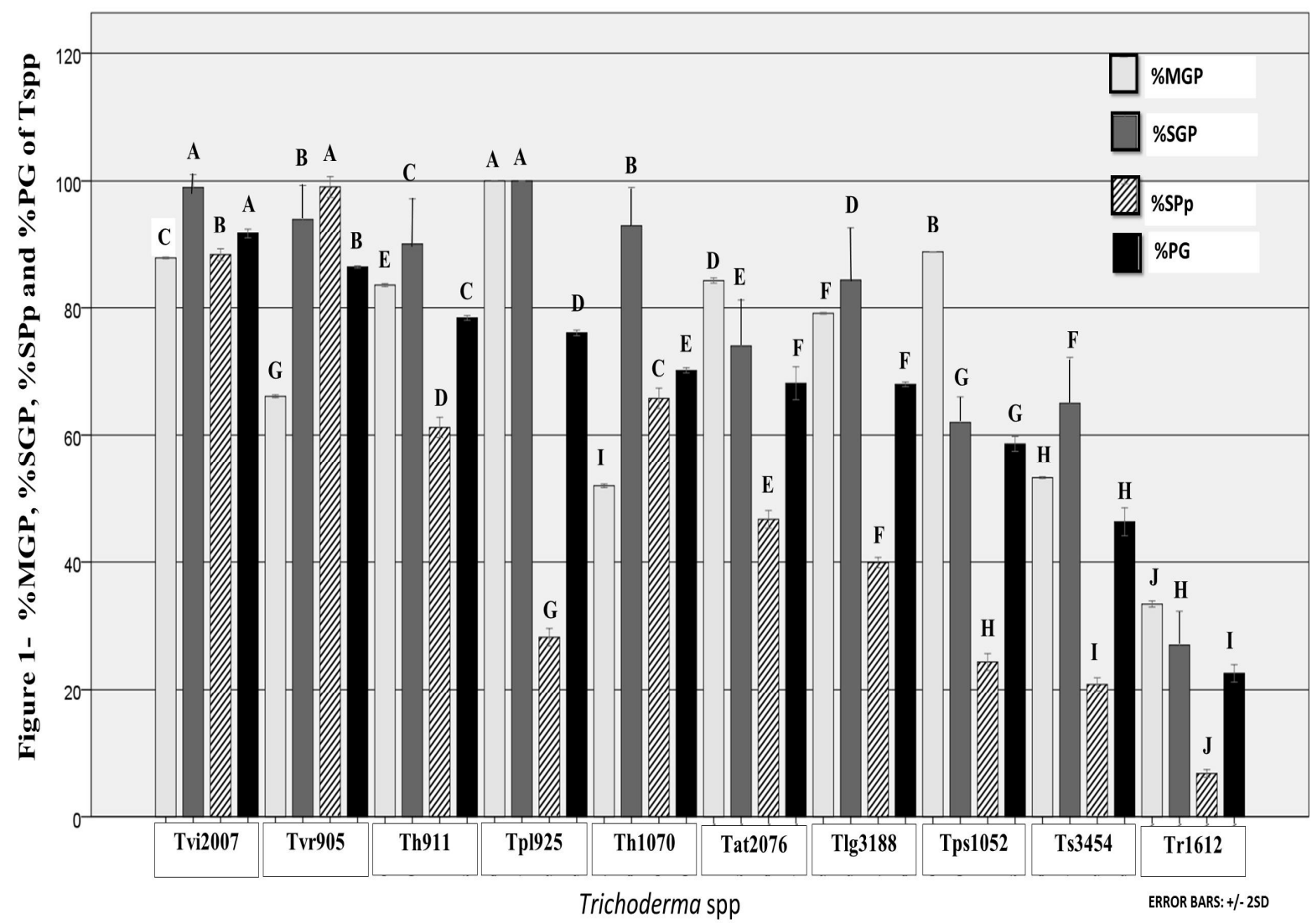

Figure 1. Mycelial Growth Potential (\%MGP), Spores Germination Potential (\%SGP), Sporulation Potential in plate (\%SPp) and Potential Growth (\%PG) of Trichoderma spp. Vertical bars represent \pm S.E. of the mean (three replicates); means followed by the same letter are not significantly different $(\mathrm{p} \leq 0.05)$ according to the Tukey test.

\subsection{Antagonistic potential (\%AP) of Tspp on Mp1441 on paired culture test}

Mycoparasitism (\%MP) and Antibiosis Potentials (\%ATP) that resulted in Antagonistic Potentials (\%AP) of Tspp to Mp114 are shown in Figure 2. All isolates which grew on the pathogen obtained a \%MP of $100 \%$ but Tlg3188 and Tr1612 which did not grow on the pathogen obtained a MP\% of 0.0. Different antibiosis potentials (\%ATP) can be observed for Tspp to Mp1441. Th911 and Tlg3188 stood out presenting a potential of the pathogen inhibition (\%ATP) of $95.53 \%$ e $93.50 \%$ respectively, being significantly different among them $(\mathrm{p}<0.05)$. Other isolates did not show the same capacity of antibiosis, but Ts3454 and Tps1052, although significantly different $(\mathrm{p}<0.05)$ got a relatively high \%ATP. Yet, it can be noted that other isolates, which presented a potential of mycoparasitism (\%MP) of $100 \%$ were not efficient to inhibit the pathogen growth (\%ATP), such as Tp1925 e Tvi2007. When simultaneously evaluated the potential of mycoparasitism (\%MP) and antibiosis (\% ATP), it is obtained the index denominated Antagonistic Potential (\%AP) of Tspp to Mp1441 (Figure 2). Th911 stood out presenting a \%AP of $97.76 \%$ ( $\mathrm{p}<0.05)$, followed by Ts3454 (94.51\%). The $\%$ AP of the others isolates gradually diminished, being the lowest $\% \mathrm{AP}$, was presented 
by $\operatorname{Tr} 1612(46.49 \%)$.

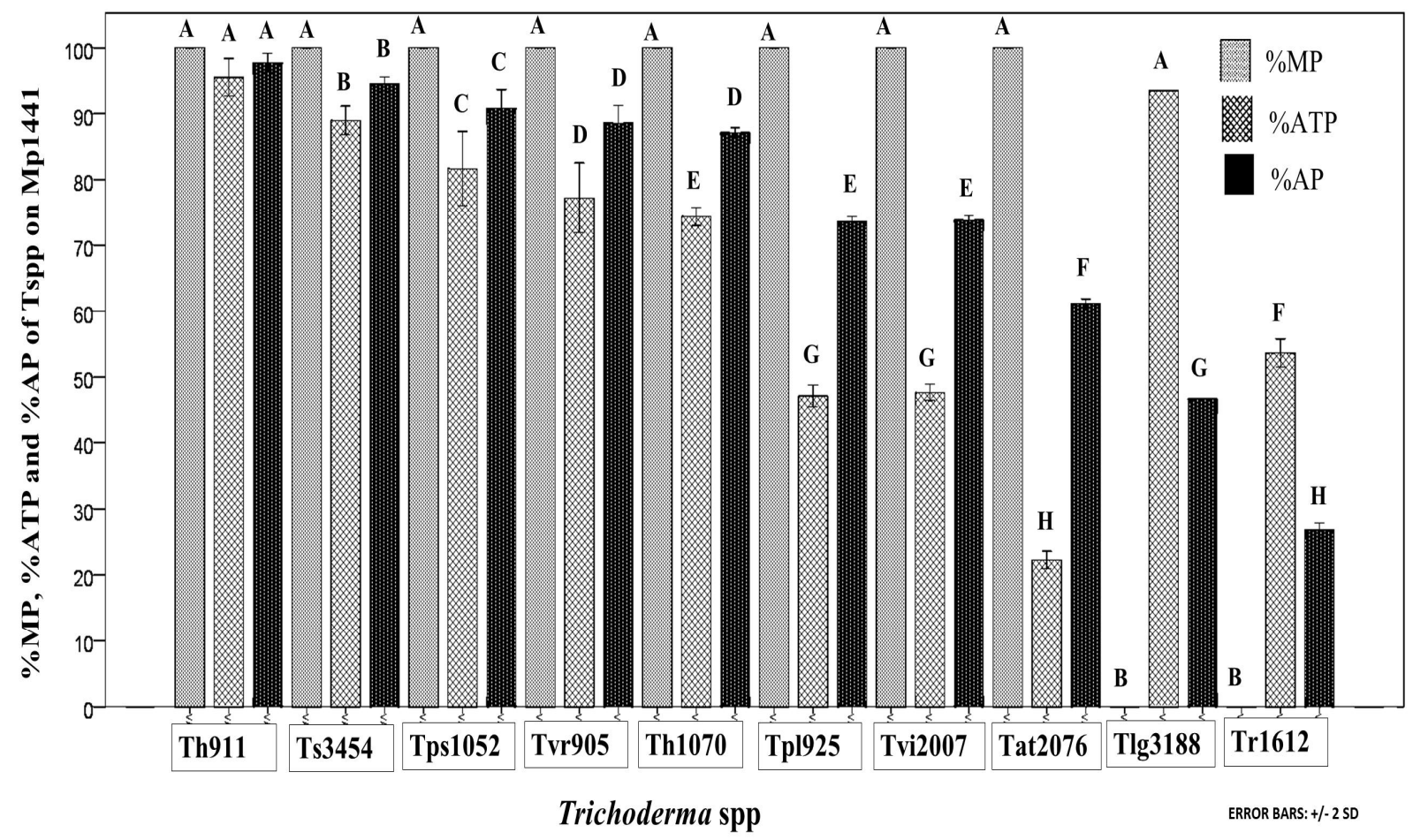

Figure 2. Mycoparasitism Potential(\%MP), Antibiosis Potential (\%ATP) and Antagonistic Potential (\%AP) of Trichoderma spp on Mp1441. Vertical bars represent \pm S.E. of the mean (three replicates); means followed by the same letter are not significantly different $(\mathrm{P} \leq 0.05)$ according to the Tukey test

\subsection{Tspp Potential of Spores production in rice (\%PSPr) as substrate}

Thrichoderma isolates were evaluated as for their spore production in rice, once this substrate is generally used in the processes of mass spore production to be used in biocontrol. Spore Production (SPr) per gram of dry substrate (spores. gds $^{-1}$ ), Potential of spore production in rice (\%PSPr) and Productivity of spores Production (\%PP-spores. $\mathrm{gds}^{-1}$. day) are depicted on Table 2. The results were significantly different for all isolates $(\mathrm{p}<0.05)$, where Th911 was the isolate that presented the best $\operatorname{SPr}\left(35.23 \times 10^{8}\right.$ spores. $\left.\mathrm{gds}^{-1}\right)$ and $\% \operatorname{PSPr}(99,53 \%)$, followed by Tps1052 (25.29. $10^{8}$ spores. $\mathrm{gds}^{-1}$ ) and \%PP of 71,45\% e Tp1925 com SPr of $19.48 \times 10^{8}$ spores. gds $^{-1}$ e $\%$ PSPr of $55.04 \%$. However, it took different periods of time to colonize the substrate, being the shorter time (3 days) showed by Th911 and Tvr905, which obtained a higher \%PP (11.74 spores. $10^{8}$. $\mathrm{gds}^{-1}$. day and 5.78 spores. $10^{8}$. $\mathrm{gds}^{-1}$. day, respectively). Tps1052, although it had been the second SPr and \%PSPr did not presented a good \%PP, once it took 5 days to colonize the substrate. Ts3454 presented the worst SPr $\left(0.37\right.$ spores. $\left.10^{8} \cdot \mathrm{gds}^{-1}\right)$ and 7 days for colonization taking a $\% \mathrm{PP}$ of 0.05 .spores. $10^{8} \cdot \mathrm{gds}^{-1}$.

Table 2. Spores Production (SPr), Potential of Spores Production (\%PSPr), colonization time and spores productivity of Trichoderma spp on rice. Data are means of three replicates and 
standard deviations are presented in parentheses. Mean followed by the same letter is not significantly different $(\mathrm{p} \leq 0.05)$ according to the Tukey test.

\begin{tabular}{lcccc}
\hline \multicolumn{1}{c}{ Tspp } & $\begin{array}{c}\text { SPr } \\
\left(\text { spores } \times 10^{8} \cdot \text { gds }^{-1}\right)\end{array}$ & \%PSPr & $\begin{array}{c}\text { Colonization } \\
\text { Time } \\
(\text { days })\end{array}$ & $\begin{array}{c}\text { Productivity } \\
\text { (spores x } 10^{8} \cdot \text { gds }^{-1} \cdot \text { day) }\end{array}$ \\
\cline { 2 - 5 } Th911 & $35.23( \pm 0.088)^{\mathrm{A}}$ & $99.53^{\mathrm{A}}$ & 3 & $11.74^{\mathrm{A}}$ \\
Tps1052 & $25.29 \quad( \pm 0.058)^{\mathrm{B}}$ & $71.45^{\mathrm{B}}$ & 5 & $5.06^{\mathrm{C}}$ \\
Tp1925 & $19.48 \quad( \pm 0.059)^{\mathrm{C}}$ & $55.04^{\mathrm{C}}$ & 5 & $3.90^{\mathrm{D}}$ \\
Tat2076 & $17.84( \pm 0.029)^{\mathrm{D}}$ & $50.41^{\mathrm{D}}$ & 5 & $3.57^{\mathrm{E}}$ \\
Tvr905 & $17.34( \pm 0.037)^{\mathrm{D}}$ & $49.00^{\mathrm{C}}$ & 3 & $5.78^{\mathrm{B}}$ \\
Tlg3188 & $10.75( \pm 0.075)^{\mathrm{F}}$ & $30.38^{\mathrm{F}}$ & 5 & $2.11^{\mathrm{F}}$ \\
Tvi2007 & $8.13( \pm 0.021)^{\mathrm{G}}$ & $22.98^{\mathrm{G}}$ & 4 & $2.03^{\mathrm{G}}$ \\
Th1070 & $7.83( \pm 0.032)^{\mathrm{H}}$ & $22.13^{\mathrm{H}}$ & 5 & $1.57^{\mathrm{H}}$ \\
Tr1612 & $1.28( \pm 0.008)^{\mathrm{I}}$ & $3.63^{\mathrm{I}}$ & 7 & $0.18^{\mathrm{I}}$ \\
Ts3454 & $0.37( \pm 0.012)^{\mathrm{J}}$ & $1.06^{\mathrm{J}}$ & 7 & $0.05^{\mathrm{J}}$ \\
\hline
\end{tabular}

\subsection{Tspp Potential for Mp1441 Biological Control (\%BCP)}

When antagonistic potential (\%AP), potential growth (\%PG) and spore production in rice (\%PSPr) are analyzed together, it is defined its potential to be used for biological control (\%BCP) of Mp144 (Figure 3). Th911 showed the best characteristics, with a \%BCP of 91.86\% when compared to the others $(\mathrm{p}<0.05)$; Tvr905 and Tps1052 presented a similar \%BCP (74.67\% and 73.72\%, respectively) ( $>>0.05)$, being $\operatorname{Tr} 1612$ the one that showed the worst result $(24.17 \%)$.

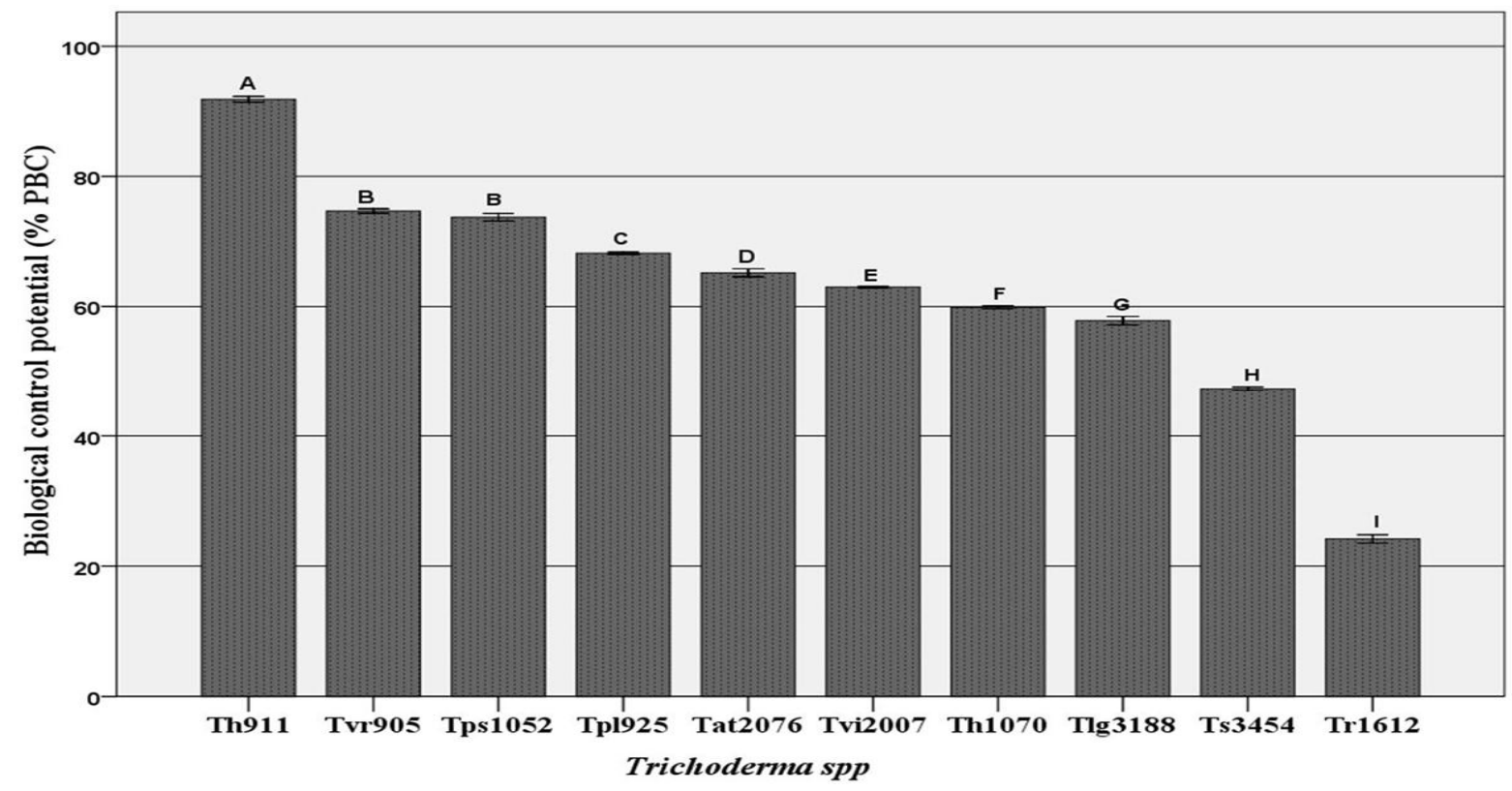

Figure 3. Biological Control Potential (\% BCP) of Tspp on Mp1441. Vertical bars represent \pm S.E. of the mean (three replicates); means followed by the same letter are not significantly different $(\mathrm{p} \leq 0.05)$ according to the Tukey test 
3.5 Sporulation of Tspp on brooms infected by Mp1441

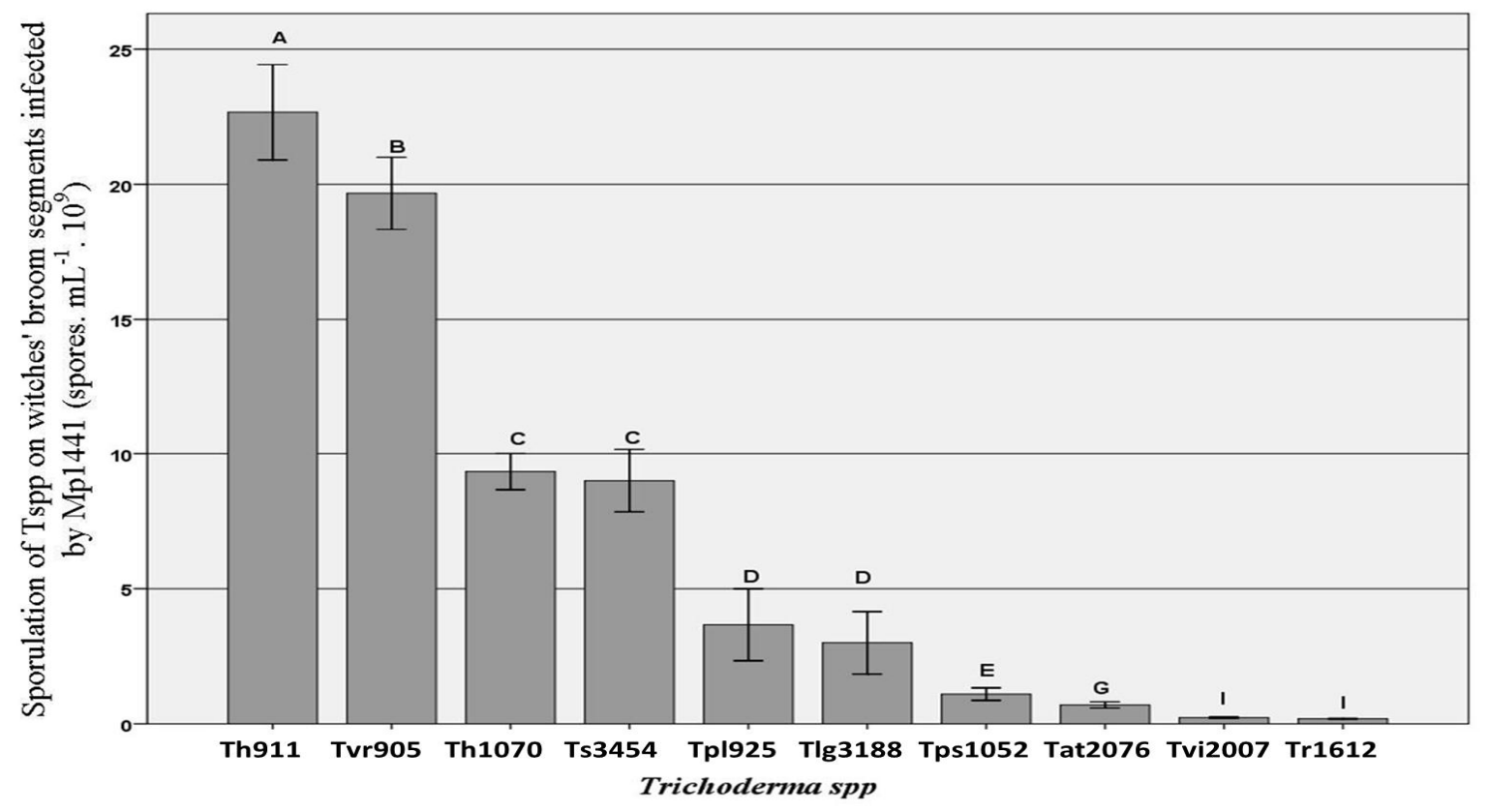

Figure 4. Sporulation of Tspp on witches' broom segments infected by Mp1441. Vertical bars represent \pm S.E. of the mean (three replicates); means followed by the same letter are not significantly different $(\mathrm{p} \leq 0.05)$ according to the Tukey test

The results presented in Figure 4 demonstrate that all the isolates of Thrichoderma spp were able to colonize the infected brooms by Mp1441, showing a variation in the spore production by segment, however; Th911 stood out $(\mathrm{p}<0.05)$ with a production of $22.67 \times 10^{9}$ spores ml ${ }^{-1}$ covering all the broom segment (Figure 5) followed by Tvr905 with a production of $19.67 \mathrm{x}$ $10^{9}$ spores. $\mathrm{ml}^{-1}$ (Figure 6). The sporulation on brooms by Th1070 and Ts3454 (Figure 6) was 9.0 and $8.67 \times 10^{9}$ spores. $\mathrm{ml}^{-1}(\mathrm{p}>0.05)$ respectively, $60 \%$ lower than the others. The other isolates showed to have to lowest capacity of colonization being the worst result presented by $\operatorname{Tr} 1612$ with a production of $0.19 \times 10^{9}$ spores $\mathrm{ml}^{-1}$.

\section{Discussion}

Trichoderma species are typically considered soil and root colonizers (Howell 2003; Harman et al. 2004; Samuels 2006) and several Trichoderma species have been extensively studied for their biocontrol potential (Harman 2000, 2004; Howell 2003; Samuels 2006). It has been known for many years that Trichoderma spp inhibit the fungal growth by three mechanisms: competition (for space and nutrients), parasitism (deriving nutrients from the host); and antibiosis (production of an inhibitory metabolite or antibiotic) (Harman 2006). While one mechanism may predominate, this does not exclude the possibility that one or both of the other two mechanisms may also play a role in the antagonistic behavior.

The confrontation of Trichoderma spp against Mp1441 by dual culture in most cases resulted in the whole covering of the pathogen colony, not allowing the visualization of its growth 
consequently the antagonist capacity to inhibit. The edition of the cultivation photos using the software Photoshop CS2 software facilitate this visualization and allow the measurement of the pathogen colony ratios and the calculus of the inhibition potential of the antagonist.

It can be verified in Figure 2 that the mechanism of antagonism by mycoparasitism (\%MP) was found to be more effective in suppressing the growth of the pathogen, once most of the isolates of Trichoderma spp evaluated presented higher values of $\% \mathrm{MP}$ when compared to the values of \%ATP, except Tlg3188 which obtained \%MP of $0.0 \%$ but presented a $\%$ ATP of 93.50 (Figure 2). From the data of Figure 2, therefore it can be hypothesized that all of the evaluated fungi probably produced an array of enzymes with antagonistic effects against Mp1441, except Tlg3188 and Tr1612. The capacity to control the growth of M. perniciosa by mycoparasitism has been widely reported as the main control mechanism, principally by isolates of T. harzianum (Sobowale et al. 2005; El-Katatny et al. 2000), T. stromaticum (De Souza et al. 2008; Samuels et al. 2000) and T. viride (Bastos 1996a). After securing the hyphae of the pathogen by aspersoria or by rolling, penetrates through cell wall by the secretion of hydrolytic enzymes such as, chitinase, $\mathrm{N}$-acetyl glucosaminidases, $\beta$-glucanases, proteases, cellulases and amylases (De Marco et al. 2003). Thus, it can be that the isolates that did not present mycoparasitism capacity did not have the necessary enzymatic complex to lies the cellular wall of the pathogen. The absence of mycoparasitism of $\operatorname{Tlg} 3188$ and Tr1612 (Figure 2) against Mp1441 suggests a non-specific interaction between them (that is Mp1441 is not included in the host range of Tlg3188 and Tr1612).

Some isolates that displayed \%MP of $100 \%$, ware also capable to inhibit (\%ATP) in different degrees $(\mathrm{p}<0.05)$ the growth of Mp1441, such as Th911, Ts3454 and Tps1052 (Figure 2), confirming the concept of enzyme biosynthesis as a mechanism of biocontrol has been expanded to include synergism between enzymes and antibiotics acting synergistically on the host (Abdel-Fattah et al. 2007). On the other hand, Tvr905, Tvi2007, Tat2076, Th1070, Tp1925 e Tvr905, presented a high capacity of mycoparasitism (\%MP of 100\%), but did not show high antibiosis capacity (\%ATP) to Mp1441 (Figure 2).

However, antibiosis can not be easily recognized or differentiated from competition in agar tests once inhibition zones indistinguishable from those caused by antibiosis can be produced by depletion of nutrients (Lockwood 1988). Hence, the results suggest that these isolates have metabolites with antifungal activity and/or not allow the pathogen growth by the mechanism of competition for space and nutrient. A large number of peptides and cyclic polypeptides antibiotics such as trichodermin, trichodermol and harzianolide are produced by Trichoderma species (Vinale et al. 2005). Other volatile and non-volatile antifungal substances, such as diterpenes, peptaibols, butenolides, furanones, pyrones, and pyridones are also produced by Trichoderma species.

Antibiosis action has also been described of T. pseudokoningii (Sobowale et al. 2005), T. harzianum (John et al. 2004), T. viride (Manjula et al. 2004), T. virens (Mukherjee et al. 2006) and T. longibrachiatum (Tarus et al. 2003) against many phytopathogens, but it is not very clear in the biocontrol of $M$. perniciosa. However; it was found antibiosis activities of Trichoderma harzianum Rifai on the spore germination and mycelial growth of $M$. perniciosa 
Stahel (Anejaa et al. 2005) and Moniliophthora roreri Cif. H.C. Evans (Bailey et al. 2008; Anejaa et al. 2005).

If the results presented were evaluated by mycoparasitism capacity (\%MP) all the isolates (except Tlg3188 and Tr1612) would represent the same potential to control Mp1441, if analyzed for capacity of antibiosis, the isolates with high potential for biocontrol of MP1441 would be Th911, followed by Tlg3188 and Ts3454 (Figure 2). This could result in a selection of isolates in detrimental to others that eventually could present both capacities. Therefore, a combination of actions results in a high level of antagonism, when compared to the level obtained by one of the isolated mechanisms (Monte, 2001). Thus, if the potential antagonist effect of Trichoderma spp has been evaluated as a summatory of the capacities of hyper-parasitism and antibiosis acting synergistically, it can be observed that Th911 and Ts3454 displaying a greater antagonistic potential (\%AP) to Mp1441 (Figure 2). These isolates got a high because they demonstrated not only mycoparasitism capacity but also high antibiosis. The \%AP of Tps1052, Tvr905, Tvi2007 and Tp1925 gradually diminish due to a decrease in their capacities of antibiosis, once all obtained a $\% \mathrm{MP}$ of $100 \%$. The low $\%$ AP of $\operatorname{Tlg} 3188$ and $\operatorname{Tr} 1612$ was due to a low potential of mycoparasitism (\%MP) presented.

The choice of an isolate must not take into account just its antagonistic characteristics, once there must be the concern with other characteristics, such as present a good production and germination of spores besides the fast and abundant mycelium production, once it constitute the invasive form of the pathogen. From the results obtained in this work regarding to the growth characteristics of Thrichoderma spp evaluated, it can be observed that Tvi2007, although it did not have a good \% AP (Figure 2), stood out not only regarding to its growth characteristics (\%MGP and \%SGP) but also sporulation (\%PSp) being the best \%PG ( $<<0.05)$ (Table 1). Tvr905, despite being similar to Th911 as for its \%PSp and \%SGP, did not show good results regarding to its mycelial growth velocity (MGV) (Table 1). On the other hand Th911, which presented the highest value of \%AP, demonstrated a regular \%PG (78.27); once its \%SPp was lower (Table 1). Ts3454 and Tps 1052 were the ones that presented the second and third higher values of \%AP (Figure 2), got an extremely low \%PG (Figure 1) because its growth and sporulation characteristics were extremely low (Table 1). If selected, it could lead the program of mass production of spores for use in biocontrol to a failure, as productivity is an indispensable factor in reduction of costs (Soares et al. 2007) and germination of spores and velocity of mycelium growth are factors that guarantee a good growth and germination in the field, thus represent an invasive form in the process of antagonism and consequently greater concentration of metabolites and/or antifungal enzymes that could be excreted (Manavathu et al. 1999).

Tr1612, besides it did not present a good \%AP (Figure 2), it also did not present good characteristics of growth and sporulation (Table 1) obtaining a low \%PG (Figure 1), not displaying in vitro the minimal conditions to be used in biocontrol.

Such data demonstrate that the fungi which presented a good \%AP do not necessarily present the best growth characteristics (\%PG), mainly as for sporulation potential showed to be a limitant factor thus reducing the final values of $\% \mathrm{PG}$. 


\section{Mll Macrothink}

Journal of Biology and Life Science

ISSN 2157-6076

2012, Vol. 3, No. 1

Therefore, one decisive factor in the selection of an isolate for spore mass production in commercial scale for biocontrol is to obtain a high productivity in the selected substrate, being the most used substrate for the production of conidia is white rice (Milner et al. 1993). Despite of Th911did have not shown a good spore production on rice (Table 2), it was the one that presented the highest spore production on rice in a short time obtaining a high productivity per day (Table 2), with a production of $35.23 \times 10^{8}$ spores.gds $^{-1}$ and a productivity of $11.74 \times 10^{8}$. spores $\operatorname{gds}^{-1}$ day $(\mathrm{p}<0.05)$ when compared to the other isolates (Table 2). On the other hand Tps1052 presented the second higher spore production on rice, taking 5 days to colonized the entire substrate, and also taking a lower productivity per day (Table 2), the opposite happened with Tvr905. Hanada et al. (2009) obtained a production of $1.02 \times 10^{8}$ conidia. $^{-1}$ after culturing Trichoderma martiale on rice grains supplemented with calcium carbonate and De Souza et al. (2006) with T. stromaticum got $7.8 \log _{10}$ conidia $\mathrm{g}^{-1}$ on rice, demonstrating the efficiency of T. harzianum 911 evaluated in the present work.

Ts3454 showed a good antagonistic potential (\%AP) to Mp1441 (Figure 2) but obtained the lowest spore production in rice $\left(0.37 \times 10^{8}\right.$ spores. $\left.\mathrm{gds}^{-1}\right)$ (Table 2). Trichoderma stromaticum is used in the formulation of Tricovab and has shown high efficiency in the witches' broom control in cocoa trees in Bahia (Brazil) (Niella 2005), however, showing problems regarding to spore production in rice, which make difficult the its production in large scale (APCD 2007).

The isolates that present the best characteristics in vitro for commercial mass production of spores to be used in biological control $(\% \mathrm{BCP})$ of Mp1441 were: Th911 ( $\mathrm{p}<0.05)$, Tvr905 and Tps1052 ( $>0.05$ ) (Figure 3), not by presenting the best individual characteristics, but by all sets of characteristics that are necessary for an isolate to be used in biocontrol, because it is meaningless having an specific characteristics and not having other essentials. Besides, it was shown that isolates of the same species could give different results as to its antagonistic characteristics, in growth and spore production, as demonstrated with isolates Th911 and Th1070, confirmed in its existing wide genetic variability among the isolates of Trichoderma of the same specie (De Souza et al. 2006).

The ability to colonize above-ground plant parts is of key interest in control of cacao diseases (Elad 1994; O’Neill 1996) and in vitro sporulation of Trichoderma species on brooms can be considered a measure of both the antagonistic capacity and environmental adaptability, since it represents the completion of a life cycle at the expense of the mycoparasitized host (Loguercio et al. 2009). Thus, the isolates of Tspp used in this work had their growth evaluated in broom segments infected with Mp1441, being the spore production by Tspp in the segments used to measure the colonization ability. By the obtained results, both Th911 and Tvr905 presented good sporulation on the broom dry segments, although; significantly different $(\mathrm{p}<0.05)$ (Figure 4), however; Tvr905 presented a low spore production in plates (Table 1), obtaining a \% BCP lower than Th911 (Figure 3).

$\%$ BCP of Th1070 and Ts3454 (Figure 3) was low mainly due to low spore productivity on rice (Table 2), but demonstrated the same capacity to sporulate in dry broom segments (Figure 4). On the other hand, Ts3454 presented a good spore production on brooms (Figure 
4), displayed low growth and sporulation capacity in plates and rice (Table 2) that results in productivity problems and a decrease in its potential of using it in biocontrol (\%BCP - Figure 3 ), as mentioned before.

Tlg3188 e Tr1612, which had not presented capacity to parasite the pathogen (\%MP of $0.0 \%$ (Figure 2) in plates, also colonized infected brooms, although weakly, what was demonstrated by the low spore production (Figure 4). This fact not necessarily proved the capacity of these fungi to produce hydrolytic enzymes capable to colonize the pathogen, but they might have colonized the broom by the secretion of hemicellulitic enzymes, such as xylanase and cellulase that degrade wood, as soon as they have reproduced.

It was not found available data in the literature regarding to the spore production on segments of brooms to compare the results here obtained.

\section{Conclusion}

It is noted through the obtained results the importance of the studies in vitro on the choice of isolates for using in the biological control of phytopathogens, once when analyzed only in vivo (in the field) some problems can arise during the mass production of spores for commercialization, because the isolates can grow well in dry brooms but do not present the necessary conditions for production, such as, problems in the production of inocula in plates, and mainly in the production of spores on rice, which guarantees the productivity of the process. According to the data displayed in the present work, Th911 e Tvr905 demonstrated to have the best desirable qualities of a fungus to be used in biocontrol of Mp1441. Trichoderma harzianum are commercialized for the control of many different diseases in many different crops (Bastos 1996ab, Manjula et al. 2004) and T. harzianum isolate has been extensively studied for biocontrol diseases (Elad 1994; O’Neill 1996). However, further studies must look for the ideal conditions of growth and sporulation for Th1070 e Ts3454, such as, alternative substrates, with different carbon sources and other kinetic conditions of growth, once they also demonstrated to present antagonistic qualities to pathogen evaluated, besides the capacity to colonize the infected brooms.

\section{References}

Abdel-Fattah G. M., Shabana, Y. M., Ismail, A. E., Rashad, Y. M. (2007). Trichoderma harzianum: a biocontrol agent against Bipolaris oryzae. Mycopathology, 164, pp.81-89. http://dx.doi.org/10.1007/s11046-007-9032-9

Aime, M. C., Phillips-Mora, W. (2005). The causal agents of witches' broom and frosty pod rot of cocoa (Theobroma cacao) form a new lineage of Marasmiaceae. Mycology, 97, pp.1012-1022. http://dx.doi.org/10.3852/mycologia.97.5.1012

Andrade, R., Ayer, W. I., Mebe, P. P. (1992). The metabolites of Trichoderma longibrachiatum. Part 1. Isolation of the metabolites and the structure of trichodimerol. Canadian Journal of Chemestry, 70, pp.2526-2535. http://dx.doi.org/10.1139/v92-320

Anejaa, M., Gianfagnaa, T. J., Hebbarb, P. K. (2005). Trichoderma harzianum produces nonanoic acid, an inhibitor of spore germination and mycelial growth of two cacao pathogens. 
Physiology and Moleculat Plant Pathologt, 67(6), pp.304-307. http://dx.doi.org/10.1016/j.pmpp.2006.05.002

APCD (2007). Aprimoramento da Produção de Cacau e seus Derivados, Relatório Técnico Final, Centro de Pesquisas do Cacau - CEPEC. Available in: www.fapesb.ba.gov.br/fapesb/relatorio_atividades (July, 2011).

Bailey, B. A., Bae, H., Strem, M. D., Crozier, J., Thomas, S. E., Samuels, G. J., Vinyard, B. T., Holmes, K. A. (2008). Antibiosis, mycoparasitism, and colonization success for endophytic Trichoderma isolates with biological control potential in Theobroma cacao. Biological Control, 46, pp24-35. http://dx.doi.org/10.1016/j.biocontrol.2008.01.003

Bastos, C. N. (1996a). Potencial de Trichoderma viride no controle da vassoura-de-bruxa (Crinipellis perniciosa) do cacaueiro. Fitopatologia Brasileira, 21, pp.509-512.

Bastos, C. N. (1996b). Mycoparasitic nature of the antagonism between Trichoderma viride and Crinipellis perniciosa. Fitopatologia Brasileira, 21, pp.50-54.

Gardener, M. B. B. and Fravel, D. R, (2002). Biological control of plant pathogens: Research, commercialization, and application in the USA. Online. Plant Health Progress doi: 10.1094/PHP-2002-0510-01-RV. http://dx.doi.org/10.1094/PHP-2002-0510-01-RV

Cheah, L. H. and Horlock, C. M. (2007). Field-applied fungicides and postharvest treatments to control asparagus diseases posing biosecurity threats to New Zealand. Plant Pathology, 60, pp.94-98.

De Marco, J. L., Valadares-, M. C., Felix, C. R. (2003). Production of hydrolytic enzymes by Trichoderma isolates with antagonistic activity against Crinipellis perniciosa, the causal agent of witches' broom of cocoa. Brazilian Journal of Microbiology, 34, pp.33-38.

De Souza, J. T., Bailey, B. A., Pomella, A. W. V., Erbe, E. F., Murphy, C. A., Bae, H., Hebbar, P. K. (2008). Colonization of cacao seedlings by Trichoderma stromaticum, a mycoparasite of the witches' broom pathogen, and its influence on plant growth and resistance. Biological Control, $\quad 46(1), \quad$ pp.36-45. http://dx.doi.org/10.1016/j.biocontrol.2008.01.010

De Souza, J. T., Pomella, A. W. V., Bowers, J. H., Pirovani, C. P., Loguercio, L. L., Hebbar, K. P. (2006). Genetic and Biological Diversity of Trichoderma stromaticum, a mycoparasite of the Cacao Witches'Broom Pathogen. Phytopathology, 96(1), pp.61-67. http://dx.doi.org/10.1094/PHYTO-96-0061

Di Verena, S. (2006). Molecular and physiological investigations of bio-controll by the genus Hypocrea/Trichoderma. Dissertation. Technischen Universität Wien, Fakultät für Technische Chemie.

Edington, L. V., Khew, K. L., Barron, G. L. (1971). Fungitoxic spectrum of benzimidazole compounds. Phytopathology, 61, pp.42-44. http://dx.doi.org/10.1094/Phyto-61-42

Elad, Y. (1994). Biological control of gray mould by Trichoderma harzianum. Crop 
Protection, 13, pp.35-38. http://dx.doi.org/10.1016/0261-2194(94)90133-3

El-Katatny, M. H., Somitsch, W. K.-H, El-Katatny, M. S., Gübitz, G. M. (2000). Production of Chitinase and $\beta-1,3$-glucanase by T. harzianum. Food Technology and Biotechnology, 38(3), pp.173-180.

Hanada, R. E., Pomella, A. W. V., Soberanis, W., Loguercio, L. L., Pereira, J. O. (2009). Biocontrol potential of Trichoderma martiale against the black-pod disease (Phytophthora palmivora) of cacao. Biological Control, 50(2), pp.143-149. http://dx.doi.org/10.1016/j.biocontrol.2009.04.005

Harman, G. E. (2000). Myth and dogmas of biocontrol changes in perceptions derived from research on Trichoderma harzianum T-22. Plant Disease, 84, pp.377-393. http://dx.doi.org/10.1094/PDIS.2000.84.4.377

Harman, G. E., Howell, C. R., Viterbo, A., Chet, I., Lorito, M. (2004). Trichoderma species-opportunistic, avirulent plant symbionts. Nature Reviews Microbiology, 2, pp.43-56. http://dx.doi.org/10.1038/nrmicro797

Harman, G.E. (2006). Overview of mechanisms and uses of Trichoderma spp. Phytopathology, 96, pp.190-94. http://dx.doi.org/10.1094/PHYTO-96-0190

Holmes, K. A., Schroers, H., Thomas, S. E., Evans, H. C., Samuels, G. J. (2004). Taxonomy and biocontrol potential of a new species of Trichoderma from the Amazon basin of South America. Mycological Progress, 3(2), pp.199-210. http://dx.doi.org/10.1007/s11557-006-0090-z

Howell, C. R. (2003). Mechanisms employed by Trichoderma species in the biological control of plant diseases: the history and evolution of current concepts. Plant Disease, 87, pp.4-10. http://dx.doi.org/10.1094/PDIS.2003.87.1.4

Jackisch-Matsuura, A. B. and Menezes, M. (1999). Caracterização morfológica e esterásica de Pythium aphanidermatum, P. ultimum e $P$. torulosum e avaliação da patogenicidade a plantas de fumo. Summa Phytopathologica, 25(2), pp.136-138.

John, S., Scott, E. S., Wicks, T. J., Hun,t J. S. (2004). Interactions between Eutypa lata and Trichoderma harzianum. Phytopathologia Mediterranea, 43, pp.95-104.

Lilly, V. G. and Barnett, N. L. (1951). Physiology of Fungi. McGraw Hill, New York, 463p.

Lockwood, J. L. (1988). Evolution of concepts associated with soilborne plant pathogens. Annual Review of Phytopathology, 26, pp. 93-121. http://dx.doi.org/10.1146/annurev.py.26.090188.000521

Loguercio, L. L., De Carvalho, A. C., Niella, G. R., De Souza, J. T., Pomella, A. W. V. (2009). Selection of Trichoderma stromaticum isolates for efficient biological control of witches' broom disease in cacao. Biological Control, 51, pp.130-139. http://dx.doi.org/10.1016/j.biocontrol.2009.06.005

Manavathu, E. K., Cutright, J., Chandrasekar, P. H. (1999). Comparative study of 
susceptibilities of germinated and ungerminated conidia of Aspergillus fumigatus to various antifungal agents. Journal of Clinical Microbiology, 37, pp.858-861.

Manjula, K., Kishore, G. K., Girish, A. G., Singh, S. D. (2004). Combined application of Pseudomonas fluorescens and Trichoderma viride has an improved biocontrol activity against stem rot in groundnut. Plant Pathology, 20(1), pp.75-80. http://dx.doi.org/10.5423/PPJ.2004.20.1.075

Milner, R. J., Rogers, D. J., Mcrae, C. M., Huppatz, R. J., Brier, H. (1993). Preliminary evaluation of the use of Metarhizium anisopliae as a mycopesticide for control of peanut scarabs. In: Pest control in sustainable agriculture. Melbourne, Australia; CSIRO, pp. 253-255.

Monte, E. (2001). Understanding Trichoderma: between biotechnology and microbial ecology. International Microbiology, 4, pp.1-4.

Mukherjee, M., Horwitz, B. A., Sherkhane, P. D., Hadar, R., Mukherjee, P.K. (2006). A secondary metabolite biosynthesis cluster in Trichoderma virens: evidence from analysis of genes underexpressed in a mutant defective in morphogenesis and antibiotic production. Current Genetics, 50, pp.193-202. http://dx.doi.org/10.1007/s00294-006-0075-0

Niella, G. R. (2005). Produção massal de Trichoderma stromaticum para o controle da vassoura-de-bruxa do cacaueiro. In: $9^{\circ}$ Simpósio de Controle Biológico-Anais. Entomological Society of Brazil, Recife-PE, p. 45.

O’Neill, T. M. (1996). Control of grapevine gray mould with Trichoderma harzianum T39. Biocontrol Science Technology, 6, pp.139-146. http://dx.doi.org/10.1080/09583159650039340

Samuels, G. J., Dodd, S. L. Lu, B., Petrini, O., Schroers, H., Druzhinina, I. S. (2006) The Trichoderma koningii aggregate species. Studies in Mycology, 56, pp.67-133. http://dx.doi.org/10.3114/sim.2006.56.03

Samuels, G. J., Pardo-Schultheiss, R., Hebbar, K. P., Lumsden, R. D., Bastos, C. N., Costa, J. C., Bezerra, J. L. (2000). Trichoderma stromaticum sp. nov. A parasite of the cacao witches' broom pathogen. Mycological Research, 104, pp.760-764. http://dx.doi.org/10.1017/S0953756299001938

Samuels, G. J., Petrini, O., Manguin, S. (1994). Morphological and Macromolecular Characterization of Hypocrea schweinitzii and its Trichoderma Anamorph. Mycology, 86(3), pp.421-435. http://dx.doi.org/10.2307/3760575

Soares, A. C. F., Sousa, C. S., Garrido, M. S., Perez, J. O. (2007). Production of streptomycete inoculum in sterilized Rice. Scientia Agricola, 64(6), pp.641-643. http://dx.doi.org/10.1590/S0103-90162007000600013

Sobowale, A. A, Cardwell, K. F., Adegboyega, C. O., Ranajit, B., Segun, G. J. (2005). Growth inhibition of Fusarium verticillioides (SACC.) nirenberg by isolates of Trichoderma pseudokoningii strains from maize plant parts and its rhizosphere. Journal of Plant Protection 
Research, 45(4), pp.249-265.

Spier, M. R. (2005). Produção de enzimas amilolíticas fúngicas $\alpha$-amilase e amiloglucosidase por fermentação no estado sólido. Dissertação de Mestrado em Tecnologia de Alimentos, Programa de Pós-Graduação em Tecnologia de Alimentos, Setor de Tecnologia. Universidade Federal do Paraná. Orientador: Prof. Dr. Carlos Ricardo Soccol, Curitiba.

Stefanova, M., Leiva, A., Larrinago, L., Coronado, M. F. (1999). Metabolic activity of Trichoderma spp isolates for a control of soil borne phytopathogenic fungi. Revista de la Facultad de Agronomia (LUZ), 16, pp. 509-516.

Tarus, P. K., Lang'At-Thoruwa, C. C., Wanyonyi, A. W., Chhabra, S.C. (2003). Bioactive metabolites from Trichoderma harzianum and Trichoderma longibrachiatum Bulletin of Chemical Society of Ethiopia, 17(2), pp.185-190.

Vinale, F., Marra, R., Scala, F., Lorito, M., Ghisalberti, E. L., Sivasithampram, K. (2005). Secondary metabolites produced by two commercial strains of Trichoderma harzianum. Journal of Plant Pathology, 87(4), pp.267-309.

\section{Copyright Disclaimer}

Copyright reserved by the author(s).

This article is an open-access article distributed under the terms and conditions of the CreativeCommons Attribution license (http://creativecommons.org/licenses/by/3.0/). 